\title{
Use of Twitter across educational settings: a review of the literature
}

\author{
Aqdas Malik ${ }^{1,2^{*}}$, Cassandra Heyman-Schrum ${ }^{3}$ and Aditya Johri ${ }^{2}$
}

\author{
* Correspondence: \\ aqdas.a.malik@aalto.fi \\ 'Department of Computer Science, \\ Aalto University, Espoo 02150, \\ Finland \\ ${ }^{2}$ Department of Information \\ Sciences \& Technology, George \\ Mason University, Fairfax, VA 22030, \\ USA \\ Full list of author information is \\ available at the end of the article
}

\begin{abstract}
The use of social media across the educational landscape is on the rise. Subsequently, the body of research on this topic is vibrant and growing. In this article, we present findings from a review of 103 peer-reviewed scientific studies published over the last decade (2007-2017) that address the use of Twitter for educational purposes across formal and informal settings. The majority of the studies reported in the literature are descriptive case studies carried out with students in North American and European higher education settings. Analysis of these studies signals Twitter as a useful tool for communication due to high accessibility, novelty, and real-time format. Students, teachers, and other stakeholders use it as a pedagogical tool to gain information, interact and engage with each other, participate in their respective communities of interests, and share their insights about specific topics. Moreover, Twitter has the potential to enhance students' learning capabilities as well as improve their motivation and engagement due to its unique features and non-traditional teaching approach. Finally, our analysis advocates for carrying out further empirical studies focusing on digital trace data and inference, particularly in the developing countries.
\end{abstract}

Keywords: Education, Learning, Teaching, Twitter, Social media, Students, Teachers

\section{Introduction}

Since their introduction around a decade ago, social media platforms and applications have become steadily popular among public and used widely for entertainment, socialization, and information seeking and sharing purposes (Dolan, Conduit, Fahy, \& Goodman, 2016; Quan-Haase \& Young, 2010; Malik et al. 2016). Twitter, which can be categorized as a specific form of social media activity - microblogging, was established in 2006 and is one of the prominent social media platforms (others include Facebook, Instagram, and Youtube) across the globe (Alhabash \& Ma, 2017). Recent statistics released by Twitter indicate that the network receives roughly 1 billion unique monthly visits and hosts around 313 million active users, with $82 \%$ being active mobile users (Twitter - Company, 2017). According to a recent study by Pew Research Center, Twitter is the fifth most popular social media platform among Americans. The study further points out that roughly one-quarter of online American adults use Twitter, with younger internet users being more active on Twitter when compared to older groups (Greenwood, Perrin, \& Duggan, 2016).

Twitter's microblogging feature allows users to publish their ideas and opinions in "real-time messaging" format by writing tweets limited to certain number of characters

(c) The Author(s). 2019 Open Access This article is distributed under the terms of the Creative Commons Attribution 4.0 International License (http://creativecommons.org/licenses/by/4.0/), which permits unrestricted use, distribution, and reproduction in any medium, provided you give appropriate credit to the original author(s) and the source, provide a link to the Creative Commons license, and indicate if changes were made. 
(initially 140 but now up to 280). Furthermore, by features such as hashtags, mentions, and replies, users can network and dialog with other Twitter users (Steckenbiller, 2016). Various aspects of Twitter practices has been researched in a number of domains including tourism (Sotiriadis \& van Zyl, 2013), sports (Gibbs, O’Reilly, \& Brunette, 2014), governance (Haro-de-Rosario, Sáez-Martín, \& del Carmen Caba-Pérez, 2016), health information (Himelboim \& Han, 2014; Malik et al. 2019), elections (Vergeer \& Hermans, 2013), and activism (Johri et al. 2018; Malik et al. 2018). Besides using Twitter for entertainment and leisure, the platform is predominantly used for social interaction, information sharing, information seeking, self-documentation, and selfexpression (Alhabash \& Ma, 2017; Liu, Cheung, \& Lee, 2010).

Even though social media platforms were not designed with the explicit purpose of supporting educational and other learning-related activities, their affordance for networking and content sharing have made them a natural fit for those purposes (Tess, 2013). Institutions of higher education, elementary and high schools, scholarly communities, as well as federal and state education agencies have actively embraced various social media platforms (Jordan, 2017; Wang, 2016). More recently, Twitter is being encompassed as an augmented scholarly communication tool for formal and informal learning. Students, scholars, and professionals from numerous academic domains use the network to connect and engage with peers and public to share discipline specific and other relevant information with an aim of pursuing their academic interests and goals (Holmberg \& Thelwall, 2014; Veletsianos \& Kimmons, 2016). A number of recent studies have also demonstrated the value, impact, and acceptance of Twitter in the context of education. For instance, Twitter has been reported to increase learning capabilities and communication (Bista, 2015; Carpenter, 2014; DeGroot, Young, \& VanSlette, 2015). Similarly, Twitter is deemed helpful in enhancing engagement and collaboration among peers, teachers, and students (Desselle, 2017; Greenhalgh, Rosenberg, \& Wolf, 2016; Osatuyi \& Passerini, 2016). On the other hand, few studies have also highlighted the negative aspects of incorporating Twitter in the educational context. These studies have emphasized the inappropriate usage, overexposure, reputation, information overload, addiction, as well as other issues associated with the content and personal privacy (Cho \& Rangel, 2017; Kinnison, Whiting, Magnier, \& Mossop, 2017; Rinaldo, Tapp, \& Laverie, 2011).

Given the exponentially increased usage by numerous entities, the potential of Twitter in education, and the wide range of studies carried out within the domain, there is a strong need to assess the state of scholarly research within the domain. Consequently, we aim to understand the usage of Twitter in various educational settings by systematically reviewing the prior research. More precisely this study examines the research on the use and perceptions of Twitter as a tool to support education and learning by various entities that include students, educationalists, and institutions. Additionally, the current review seeks to identify the obstacles associated with the usage and adoption of Twitter across different setups.

\section{Methods}

\section{Search strategy}

The process of article search and selection followed the PRISMA Statement (Preferred Reporting of Items for Systematic Reviews and Meta-Analyses) (Moher et al., 2009). As 
an initial step of the search strategy, we conducted search in a number of general as well as education focused scholarly databases including ERIC, EBSCOhost (Academic Search Complete), ProQuest, EditLib, Web of Science, ScienceDirect, and PsycINFO. All the studies identified through the database search were evaluated based on the topical relevance and established screening criteria. As an additional step, a nonsystematic search was carried out for the articles that were not identified through initial systematic search. In this step, we carried out backward referencing for relevant literature in the text of the articles that were identified through systematic search criteria by using Google Scholar. All the searches were carried out between March 25, 2017, and April 3, 2017. We restricted our search for the last 10 years as Twitter was launched in 2006. During the search process, the following search terms were used: "twitter", "learning", "learn", "education", "educate", and "educating".

\section{Inclusion and exclusion criteria}

All the peer-reviewed studies published in scholarly journals during the last ten years (2007-2017) that asses the usage of Twitter in educational and learning context were included in the review. There was no restriction based on the methodology, geographical origin, or quality of the publication forum.

Studies assessing social media in general, other social media platforms (e.g. Facebook, YouTube etc.) as well as studies assessing Twitter together with other social media/ learning/microblogging platforms (e.g. MOOC, EdModo) were excluded from the review. Furthermore, commentaries, editorials, letters, and newspaper articles were not accounted for the current review. Studies that were written in languages other than English, conference proceedings, book chapters, theses, and dissertations, and papers that were not accessible for full text were also excluded. A complete list of inclusion and exclusion criteria is outlined in Table 1.

\section{Study selection}

The preliminary search carried out through scholarly databases yielded 2434 results, of which 1121 were excluded after title reviewing. The initial exclusion includes duplicate

Table 1 Inclusion and exclusion criteria

\begin{tabular}{|c|c|c|}
\hline Criterion & Inclusion & Exclusion \\
\hline Timeframe & $2007-2017$ & Studies outside the inclusion dates \\
\hline Language & English & $\begin{array}{l}\text { Studies in any other language than } \\
\text { English }\end{array}$ \\
\hline Article type & $\begin{array}{l}\text { Original research, published in a } \\
\text { peer-reviewed journal }\end{array}$ & $\begin{array}{l}\text { Conference papers, book chapters, } \\
\text { editorials, letter, discussions, } \\
\text { newspaper articles. Papers that were } \\
\text { not original research or published in } \\
\text { peer-reviewed journals }\end{array}$ \\
\hline Focus of the study & $\begin{array}{l}\text { Twitter usage for education and } \\
\text { learning in academic context }\end{array}$ & $\begin{array}{l}\text { Twitter usage for education and } \\
\text { learning in another context. } \\
\text { Editorials, discussions, and personal } \\
\text { opinions }\end{array}$ \\
\hline Platform & $\begin{array}{l}\text { Articles findings overwhelmingly } \\
\text { relate to Twitter usage and adoption } \\
\text { for learning and education }\end{array}$ & $\begin{array}{l}\text { Articles presenting social media in } \\
\text { general or a token/passing reference } \\
\text { to Twitter for education and learning }\end{array}$ \\
\hline
\end{tabular}


articles and those deemed clearly irrelevant based on the title of the paper. The remaining 1313 articles went through abstract reviewing, with the 708 articles that did not meet the inclusion criteria being excluded. 605 articles together with 15 articles manually selected by snowball search (backward referencing) methodology were assessed for full-text review. After performing the review of full-text based on eligibility criteria a total of 103 papers were selected for the final assessment. An overview of the articles selection process is illustrated as a PRISMA flow-chart in Fig. 1.

\section{Data extraction}

Information was collected on authors' affiliation, publication forum, database sources, keywords, issues addressed, sampling characteristics, study context and domain as well

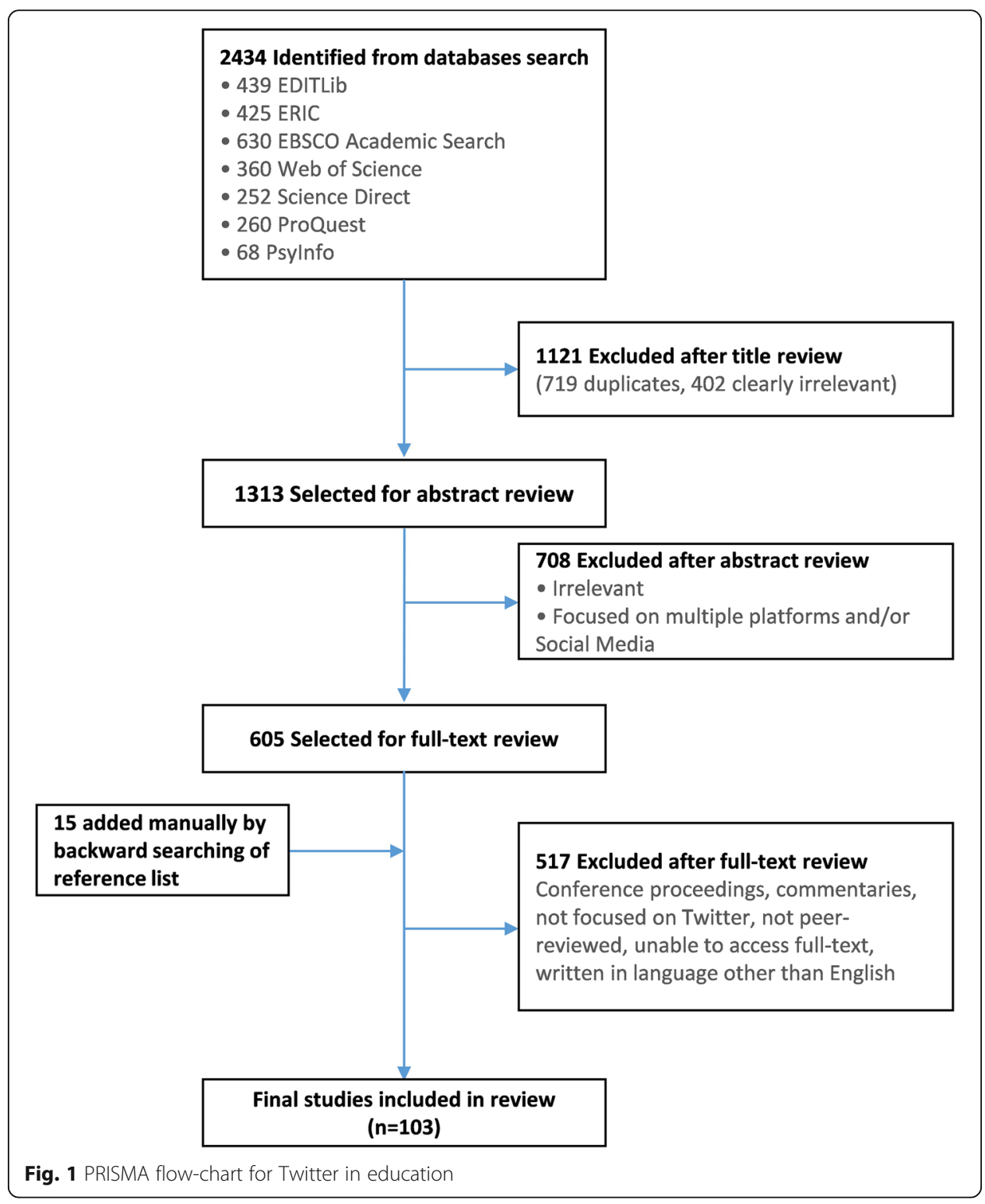


as the setup country. Furthermore, research design and approach, data collection methods and analysis, and key findings (including limitations and future directions) were also collected. Later on, the data was cross-checked independently by two reviewers and any disagreements were resolved through discussion.

\section{Findings}

\section{Descriptive features of the studies}

\section{Geographical distribution}

A majority of the studies $(N=60)$ were carried out in the USA. Likewise, most of the authors $(N=336)$ were affiliated with a USA based institution. Subsequently, authors from the UK $(N=34)$, Canada (17) and Spain $(N=15)$ contributed to these studies as well as the study setups in these countries. We also grouped the countries to assess the contributions region-wise; we found that none of the authors or the context of the study were from Africa or South America. Detailed information about the authors' affiliation and study setup is presented in Table 2.

\section{Contextual distribution}

In order to get a thorough understanding of the context, we identified the actual place of the study setup (see Table 3 ). The majority of the studies (80.6\%) were carried out in higher educational institutes, including colleges and universities. Roughly one out of ten studies was carried out in schools (9.7\%). The rest of the studies were carried out online, at a conference, or at another educational institute.

Table 2 Geographical distribution of author's affiliation and study context

\begin{tabular}{llll}
\hline Region & Country & Authors affiliation & No. of studies \\
\hline North America & USA & 336 & 60 \\
Europe & Canada & 17 & 4 \\
& Portugal & 2 & 1 \\
& Spain & 15 & 7 \\
& UK & 34 & 9 \\
& Germany & 2 & 0 \\
& Netherlands & 1 & 0 \\
& Ireland & 1 & 1 \\
& Turkey & 2 & 1 \\
Oceania & Australia & 4 & 2 \\
Asia & New Zealand & 1 & 1 \\
& Japan & 2 & 2 \\
& Malaysia & 1 & 1 \\
Not mentioned & Singapore & 5 & 1 \\
Middle East & Korea & 3 & 1 \\
& Saudi Arabia & 1 & 1 \\
& Israel & 2 & 13 \\
& & &
\end{tabular}


Table 3 Frequency (Percentage) of study context

\begin{tabular}{ll}
\hline Context & Corpus \\
\hline Higher education institution & $83(80.6 \%)$ \\
School & $10(9.7 \%)$ \\
Online & $4(3.9 \%)$ \\
Conference & $3(2.9 \%)$ \\
Misc. educational institute & $3(2.9 \%)$ \\
\hline
\end{tabular}

\section{Temporal distribution}

Analyzing the year of each publication indicates the growing interest of scholarly community towards the subject. There is a steady increase in the number of articles during the last five years (see Fig. 2.). Extrapolating from the nine articles already published during first four months of 2017 suggests that the upward trend will continue.

\section{Demographics of study participants}

Students comprise an overwhelming majority of the study participants $(N=74)$. Professors and teachers were subjects in 14 studies. Table 4 provides additional details of participant demographics.

We also identified the academic disciplines within which the studies were conducted. A large portion of the studies was conducted with participants within the applied sciences $(N=26)$ and education $(N=22)$ domain followed by participants in multidisciplinary fields $(N=19)$. Looking further into sub-fields, interestingly, 21 studies were carried out within medicine. A detailed description of the study disciplines together with the number of respective studies is listed in Table 5.

Slightly less than half $(N=48)$ of these studies used mixed methods research approach. Meanwhile, 35 studies were quantitative, with the remaining 20 being qualitative in nature. With respect to research design, a majority of the studies were case studies $(N=76)$ carried out with a confined set of participants e.g. students within a classroom. Digital trace data $(N=12)$ and field surveys $(N=11)$ were the second most used research designs, whereas, observational $(N=2)$ and cross-sectional design $(N=2)$ were adopted by the rest of the studies.

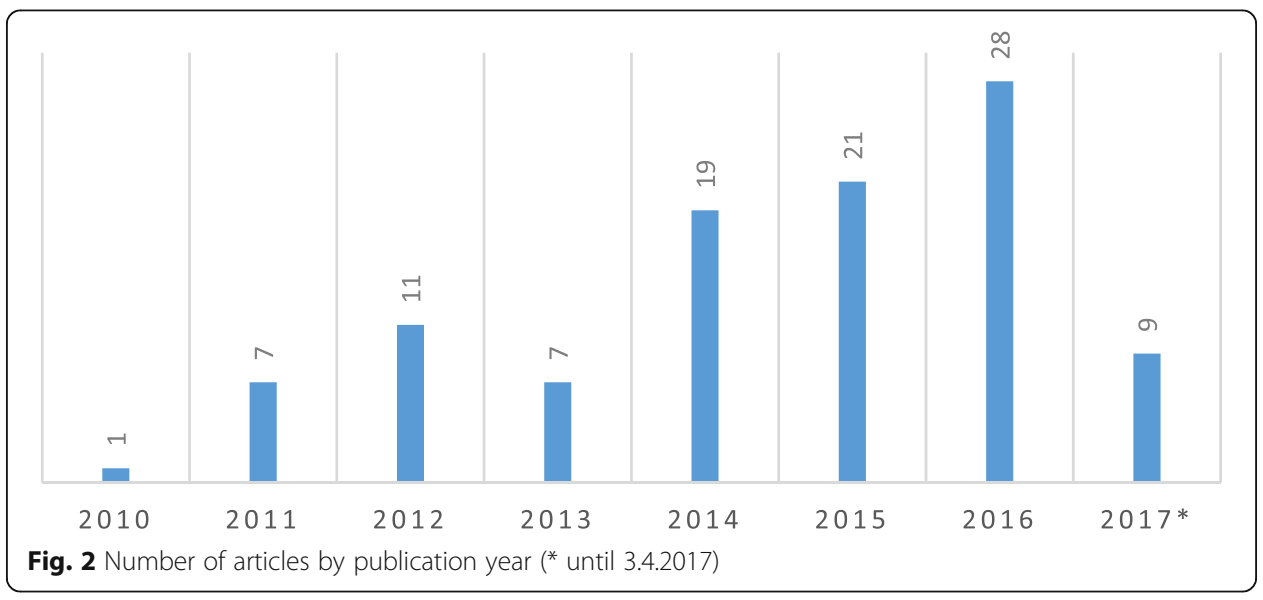


Table 4 Study participants

\begin{tabular}{lc}
\hline Study participants & Corpus \\
\hline Students & 74 \\
Professors/Teachers & 14 \\
Pre-service teachers/nurses & 8 \\
Educators & 3 \\
School admins & 2 \\
Surgeons & 1 \\
Researchers & 3 \\
Conference participants & 1 \\
Institutional Twitter account & 3 \\
Not defined & 1 \\
\hline
\end{tabular}

\section{Twitter in classroom}

Our review postulates that Twitter has been deemed a supportive tool within the classroom and has a strong potential as a technology-enabled learning instrument. Majority of the reviewed studies point out that implementing Twitter improved not only students learning, motivation, engagement, and communication but teaching as well, all of which leads towards creating a more resourceful classroom environment.

Table 5 Frequency of academic disciplines

\begin{tabular}{|c|c|c|}
\hline Academic discipline & Sub-field & Number of studies \\
\hline \multirow[t]{2}{*}{ Humanities } & Language & 7 \\
\hline & History & 1 \\
\hline \multirow[t]{5}{*}{ Social Sciences } & Social Science & 6 \\
\hline & Social studies & 1 \\
\hline & Psychology & 1 \\
\hline & Media & 1 \\
\hline & Communications & 1 \\
\hline \multirow[t]{5}{*}{ Business } & Marketing & 5 \\
\hline & Management & 2 \\
\hline & Economics & 1 \\
\hline & Accounting & 1 \\
\hline & Management & 1 \\
\hline \multirow[t]{2}{*}{ Arts } & Arts & 1 \\
\hline & Music & 1 \\
\hline Natural Sciences & Biology & 1 \\
\hline \multirow[t]{4}{*}{ Applied Sciences } & Physical Science & 1 \\
\hline & Sports & 1 \\
\hline & Technology & 3 \\
\hline & Medicine & 21 \\
\hline Education & Education & 22 \\
\hline Multi-disciplinary & - & 19 \\
\hline Not defined/not applicable & - & 2 \\
\hline
\end{tabular}




\section{Learning}

With the implementation of Twitter into educational settings, the key focus of the prior research has been on understanding if it helps students learn and if so, how? Most of the studies have found that Twitter is an effective learning tool, especially in the context of formal learning. Learning through digital technologies, especially via Twitter, has been recognized as one of the desired and enjoyable tool by students (Diug, Kendal, Ilic, et al., 2016; Hull \& Dodd, 2017; Welch \& Bonnan-White, 2012). Establishing a network for the students from which they can reach out and improve their learning experience is strongly facilitated by Twitter (Anthony \& Jewell, 2017; Bledsoe, Harmeyer, \& Wu, 2014; Hennessy, Kirkpatrick, Smith, \& Border, 2016; Marín \& Tur, 2014). As a platform, Twitter provides the space to improve their skill set, communicate with peers and teachers, think creatively, and at the same time have fun while learning (Al Harbi, 2016; Becker \& Bishop, 2016; Bledsoe et al., 2014; Kassens, 2014; West, Moore, \& Barry, 2015).

Twitter's mixed media format (e.g. pictures, videos, and text) was also considered useful for conceptual learning (Buzzelli, Bissell, \& Holdan, 2015; Mysko \& Delgaty, 2015; Tur \& Marín, 2015). It was also attributed to be highly effective for language learning as it provided more access to the language related resources and interesting ways to practice it (Fewell, 2014). For the most part, respondents in a number of studies reacted positively to its inclusion in their courses (Jones et al., 2016; Lowe \& Laffey, 2011; Luo, 2016; Tur \& Marín, 2015), however, to make learning more effective and efficient, teachers and educators must explain its use within the course and how they expect it to be used (Lackovic, Kerry, Lowe, \& Lowe, 2017).

The platform is also deemed supportive for educators as it provides them opportunities to learn. Twitter enables them to learn more about innovative and effective teaching methods as they connect with other educators that was not likely otherwise (Davis, 2015). With its professional networking availability, Twitter also helps academics learn more about their fields from domain specialists (Cho \& Rangel, 2017; Hitchcock \& Young, 2016).

\section{Motivation and engagement}

Due to its novel format, introducing Twitter into classrooms frequently had the effect of increasing the motivation and engagement of the students and faculty involved. A number of studies point out that students often found the Twitter-based instructions and activities enjoyable, which increased their motivation and excitement for the course in general (Booth, 2015; Elavsky, Mislan, \& Elavsky, 2011; Feliz, Ricoy, \& Feliz, 2013; Kassens-Noor, 2012). As they learned more about Twitter, it helped them to engage better (Mercier, Rattray, \& Lavery, 2015; Osatuyi \& Passerini, 2016) that lead to increased motivation to participate within classroom (Ricoy \& Feliz, 2016; Yakin \& Tinmaz, 2013).

The online format also increased students motivation to participate by allowing them to post and share in a comfortable space, which in turn eased in-class discussions (Halpin, 2016; Luo \& Franklin, 2015; Tiernan, 2014). Within the language learning context, the affordance for microblogging and involvement in a community increased their motivation to learn the language as well (Fewell, 2014; Kim, Park, \& Baek, 2011). It also tended to help engage the students and staff together, allowing for a more holistic and active learning community (Junco, Heiberger, \& Loken, 2011). Finally, for academics, Twitter's comprehensive format engaged them further and renewed their professional 
vigor (Cho \& Rangel, 2017; Jalali, Sherbino, Frank, \& Sutherland, 2015). To sum up, the platform shows the potential to be used as an engagement tool in the future, but one must be aware that students' motivation can be unpredictable especially if used voluntarily; hence, the implementation should be planned well ahead.

\section{Communication affordance}

Prior work also indicate that the use of Twitter in classrooms is supportive in increasing the communication not only among participants within classroom settings but with a larger professional community as well. Twitter amplifies communication among these entities by supporting collaboration and starting conversations (Carpenter, 2014; Junco, Elavsky, \& Heiberger, 2013). Furthermore, its 140-character limit allowed students in practicing thoughtful communication more concisely (Lowe \& Laffey, 2011). Within various classrooms, students regularly communicated through hashtags, relevant or interesting content, responding to one another, and tweets about the course contents, which increased communication among students and faculty (Hull \& Dodd, 2017). In addition to the classroom effects, there was a positive correlation found between the amount of Twitter usage and peer communication (Evans, 2014). Throughout the studies, those students who actively participated gradually began to realize Twitter as a communication tool that can support their learning than just using it for social interactions (Helvie-Mason \& Maben, 2017).

Moreover, Twitter also provides a convenient way to collaborate on assignments outside of class and to find intellectually stimulating interactions they would not have otherwise had (Gooding, Yinger, \& Gregory, 2016; Hitchcock \& Young, 2016; Juhary, 2016). According to Lin, Hoffman, \& Borengasser, 2013, the collaboration among students only occurred when prompted by a professor or authoritative figure, while another study by Osatuyi and Passerini (2016) found the exact opposite to be true. Due to the varied findings, this may be an important area to continue research.

For teachers, it also serves as a convenient means to regularly interact with other teachers who may be limited by distance in order to seek and share insights into teaching practices and informational resources (Carpenter, 2014; Carpenter, 2015; Carpenter \& Krutka, 2015; Davis, 2015; Gonzalez \& Gadbury-Amyot, 2016; Greenhalgh et al., 2016; Hsu \& Ching, 2012). It also supports multidirectional communication which allows for the constant, real-time flow of information from the professional and educational sectors (Andrade, Castro, \& Ferreira, 2012; Goff et al., 2016; Kassens, 2014; Segado-Boj, Domínguez, \& Rodríguez, 2015; Wang, 2016). The platform also supported teachers in assessing difficulties that students faced with the topics at hand (Cohen \& Duchan, 2012) and allowed the teachers to continue answering questions and sharing vital information even after the class has ended, therefore extending the pedagogical interaction beyond the class.

\section{Teaching}

Whilst most of the research has been focused on the effects of Twitter on student learning and engagement, some studies have examined its effect on teachers and the effectiveness of using the platform for teaching. A number of studies have found that it is pedagogically supportive and appropriate. These studies endorse that Twitter not 
only supplements traditional learning material and research methods but also supports effective and appropriate use of social media (Andrade et al., 2012; Clarke \& Nelson, 2012; Halpin, 2016; Menkhoff, Chay, Bengtsson, Woodard, \& Gan, 2015; Rinaldo et al., 2011; Yakin \& Tinmaz, 2013). Twitter is also realized as an important platform by teachers as it digitally connects them with students, allowing them to better understand the topics covered and shape the material they are teaching more effectively (Desselle, 2017; Gonzalez \& Gadbury-Amyot, 2016; Hull \& Dodd, 2017).

With regards to sharing information, Twitter has also shown potential to be far more effective than traditional teaching approaches (Kassens, 2014; Segado-Boj et al., 2015). The literature further lays out a number of techniques that can be applied by teachers to effectively engage students in learning through Twitter. For instance, in order to reach out to students and engage them in the classroom, teachers can assign students to compose regular tweets with hashtags, discuss interesting tweets, and promptly reply to students questions and other course information (Hull \& Dodd, 2017; Pollard, 2014). However, when implementing Twitter as a tool for teaching, educators need to plan carefully in advance, be clear in their instructions and consider the limitations of the tool as well (Osgerby \& Rush, 2015; Williams \& Whiting, 2016).

\section{Auxiliary support}

Outside of the classroom, Twitter has provided many useful additional advantages to students and teachers alike, allowing for professional development and networking opportunities, co-curricular learning, support at conferences, greater information sharing, and overall accessibility.

\section{Professional development and networking}

One of the prominent findings in the literature was the positive effects that Twitter had on the professional development and peer-networking of the observed participants. The platform supported both students and educators to build connections, a community, and follow professionals in respective fields (Anthony \& Jewell, 2017; Draper, Buzzelli, \& Holdan, 2016; Jacquemin, Smelser, \& Bernot, 2014; Mysko \& Delgaty, 2015; Nicholson \& Galguera, 2013). Twitter not only supports building peer networks but professional ones as well, in which a variety of scholarly information and resources can be shared and followed. This aspect has been experienced extensively, notably in the medical domain (nursing and surgical community), where the information shared is helpful for both students and professionals alike. For instance, Twitter facilitates the medical students and faculty to follow and connect to domain-specific and patients communities, current events, networking with peers and experts, and develop future aspirations (Booth, 2015; Goff et al., 2016; Jones et al., 2016; Reames, Sheetz, Englesbe, \& Waits, 2016; Sinclair, McLoughlin, \& Warne, 2015; Visser, Evering, \& Barrett, 2014).

Teachers from a number of domains also reported using Twitter more for professional development than within classrooms, which reinforced their professional vigor and commitment to work (Cho \& Rangel, 2017; Greenhalgh et al., 2016; Visser et al., 2014; Wesely, 2013). Research also points out that in recent years, Twitter has emerged as a platform for civic engagement and accessible political information, where scholars 
share information in order to promote their own practices and research agenda (Nicholson \& Galguera, 2013; Veletsianos, 2012).

Students who used Twitter also found it helpful within the classroom, as it provided support through peer-networking (Hennessy et al., 2016). After getting familiar with Twitter in the classroom, some of the students continue further by using it as a career building tool. These students used the platform to follow and network with professionals in their respective fields, and anticipated using Twitter in the future for professional development along their careers (Carpenter, Tur, \& Marín, 2016; Jacquemin et al., 2014; Tur, Marín-Juarros, \& Carpenter, 2017; Waldrop \& Wink, 2016). Another study by Nicholson and Galguera (2013) found that Twitter also aided students into the workforce transition. Whilst there are many positive reactions to the professional development provided by Twitter, a study by Lackovic et al. (2017), points out that experts and leading Twitter users dominate the platform, not allowing students to participate in the conversation which renders it far less effective. Overall, the majority of the studies have found that exposure to Twitter tends to improve participants opinions of its use as a tool for professional development and networking.

\section{Information sharing}

Twitter was also recognized useful for easy resource and information sharing to a wide breadth of people, more so than traditional classroom teaching methods (Goff et al., 2016; Kassens, 2014; Lin et al., 2013; Stephens \& Gunther, 2016). Scholars covered a multitude of topics and at the same time promoted their own research and information about their classrooms. On the other hand, students shared relatively limited information, as they were typically the recipients of information (Kimmons \& Veletsianos, 2016; Knight \& Kaye, 2016; G. Veletsianos, 2012). Twitter is also deemed as one of the potential tools for disseminating information to public by many state education agencies (Kimmons, Veletsianos, \& Woodward, 2017; Segado-Boj et al., 2015; Wang, 2016). However, despite Twitters' affordance of two-way communication, the information tend to come in the form of a monologue by most of these institutions (Kimmons et al., 2017; Knight \& Kaye, 2016).

Research also describe how Twitter use for information sharing purposes support users in various educational context. For instance, respondents used the platform for advocacy, keeping up with current issues, professional information, news, and exposure to new ideas (Camiel, Goldman-Levine, Kostka-Rokosz, \& McCloskey, 2014; Greenhalgh et al., 2016; Nicholson \& Galguera, 2013; Rehm \& Notten, 2016). In classes, it provided an online forum that made sharing resources and information far easier and was considered a useful tool, especially in obtaining supplemental material (Desselle, 2017; Juhary, 2016; Lin et al., 2013; Stephens \& Gunther, 2016). This led to students demonstrating improvement in classes with Twitter use than those without it (Fewell, 2014). Many of those who participated in the studies at hand enjoyed having access to a constant, rapid flow of information. This rapid communication allowed students to feel as though they had greater access to staff and could gain information from them in a timely manner (Cho \& Rangel, 2017; Diug et al., 2016). Twitter also provided students a more comfortable atmosphere for information sharing. Students also felt more at ease with sharing information and opinions in person, also allowing students to comment on each other's posts sharing 
further insights (Gooding et al., 2016; Lin et al., 2013; Sinclair et al., 2015; Tiernan, 2014; Wright, Frame, \& Hartzler, 2014). With respect to the quality of information, the resources available on Twitter were considered more reliable and relevant. Classes that were taught how to properly use Twitter to find the information witnessed a significant decline in Google searches and an increase in the usage of reputable sources (Halpin, 2016).

\section{Usage at the conferences}

Though limited, research has also addressed the usage of Twitter at academic conferences. Twitter is often referred as intellectually stimulating and a worthy platform to disseminate new knowledge and information (Jalali et al., 2015). However, the use of Twitter in conference settings reported low uptake and usage, as well as several barriers attributed to its use. The study by Kimmons and Veletsianos (2016) indicates that few students and professors used Twitter at the conferences. Most of the professors who used Twitter at conferences reasoned it for networking purposes rather than communicating (Kimmons \& Veletsianos, 2016; Li \& Greenhow, 2015). Academics posted on the platform in order to cover information and connect with communities, meanwhile non-academic counterparts posted to positively promote topics and to critique periodically (Kimmons \& Veletsianos, 2016).

\section{Social aspects}

The literature also emphasizes various social aspects associated with Twitter-based instruction that lead to a number of benefits. It allows for stronger community building and networking, as well as a reduction in shyness and isolation. Some of the literature also highlights demographic variation in the usage and adoption of Twitter for educational purposes.

\section{Communities of practice}

A benefit of integrating Twitter into the learning environment, especially in the classroom, is the sense of community it facilitates by supporting active collaboration and opportunities to communicate and share information inside and outside of the classroom (Becker \& Bishop, 2016; Booth, 2015; Bull \& Adams, 2012; Carpenter \& Krutka, 2015; Lomicka \& Lord, 2012). Twitter allows students to connect with each other as well as interact with instructors and professionals, which leads to the creation of social and professional support networks (Anthony \& Jewell, 2017; Camiel et al., 2014; Cho \& Rangel, 2017; Visser et al., 2014).

Twitter also facilitated a space for students to network and share information confidently with the community (Becker \& Bishop, 2016; Mysko \& Delgaty, 2015; Veletsianos, 2012). A number of students further report that Twitter's hashtag feature is highly effective in building these communities, as it allows them to build connections and feel as though they belong to the community (Bledsoe et al., 2014). Courses that include Twitter usage have been found to have a significantly stronger sense of a classroom community and comfort with peers than those without it (Clarke \& Nelson, 2012; Rohr \& Costello, 2015; Ross, Banow, \& Yu, 2015; Smith \& Tirumala, 2012; Wright et al., 2014). Participation in the community increased their engagement, and the meaningfulness of what the students were learning (Bull \& Adams, 2012; 
Evans, 2014; West et al., 2015). The sense of community in the online environment also enhanced students' self-confidence. For instance, studies by Cohen and Duchan (2012) and Kinnison et al. (2017), report confidence facilitation via Twitter, as the platform allowed more timid students to participate as much as others.

For teachers, Twitter allowed them to create a new type of social network that digitally spanned farther distances. This created a unique experience that allowed them to interact and collaborate professionally with colleagues outside of their immediate communities (Davis, 2015; Greenhalgh et al., 2016; Munoz, Pellegrini-Lafont, \& Cramer, 2014). Studies also report relationship improvement between instructors and students, as the platform promotes open and real-time communication (DeGroot et al., 2015; Diug et al., 2016; Domizi, 2013; Gonzalez \& Gadbury-Amyot, 2016; Rehm \& Notten, 2016). Furthermore, Twitter goes beyond simply connecting with classmates and support learners to follow and build a community for the purpose of learning. For instance, students studying a foreign language can interact with native speakers and know more about their culture. On Twitter they can practice with convenience outside of class while remaining in close contact with those who speak their first language (Fewell, 2014; Kim et al., 2011; Steckenbiller, 2016). Finally, Twitter is also supportive to educationalists other than students and teachers. For instance academic administrators use Twitter to increase their leadership by building a community that focuses on education (Sauers \& Richardson, 2015).

\section{Combatting shyness and isolation}

In addition to creating a community, Twitter serves as a platform to help students combat isolation and shyness. Twitter supports the participation of shy students in a more active manner (Cohen \& Duchan, 2012; Kinnison et al., 2017; Mercier et al., 2015; Tiernan, 2014). Many students expressed that they would not have shared their opinions otherwise if they had not been using Twitter (Fox \& Varadarajan, 2011). Due to its capability to hold online conversations, it diminishes the sense of isolation in online classes which strongly supports the personal development of individual students (Munoz et al., 2014; Rehm \& Notten, 2016). Similarly, the study by Wright (2010) also indicates that Twitter is helpful in reducing isolation and boosting self-confidence among the learning community.

\section{Demographic variations}

With regards to gender, males and females used Twitter equally. However, younger groups use and regard Twitter's appropriateness for educational purposes far more than the older ones (Draper et al., 2016; Feliz et al., 2013). Furthermore, studies also reported differences between the usage of students, professors, academics, and scholars as well. Students tended to use Twitter less at conferences and for learning activities than others (e.g. Professors), but using it more for non-academic purposes (Kimmons \& Veletsianos, 2016; Knight \& Kaye, 2016; Li \& Greenhow, 2015; Veletsianos \& Kimmons, 2016). Students tended to exemplify their learning through Tweets and interactions, but not in an overt way (Prestridge, 2014) as they often refer to technology in a more general sense than professors and other professionals within academia (Veletsianos \& Kimmons, 2016). Professors tended to use Twitter for specific academic 
purposes instead, often focusing on specific academic subjects (Knight \& Kaye, 2016; Veletsianos \& Kimmons, 2016). On the other hand, administrators in academia are found to have the majority of their usage focused on promoting community, educational issues and enhancing their leadership (Sauers \& Richardson, 2015). Moreover, academic administrators appeared to focus on their own reputations rather than its utility to students, which can consist of posting Tweets of a wider variety and attempting to reach a larger community (Knight \& Kaye, 2016).

\section{Usage outcomes and perceptions}

A number of studies also emphasize the outcomes and perceptions associated with the usage of Twitter in the educational context. Overall, most of the studies indicate positively about a number of aspects including retention rates, student grades, increased credibility for teachers, and the intentions of using Twitter in future. However, a few studies also point out concerns and adverse reactions as well as reasons behind hindering the usage and adoption associated with Twitter for educational purposes.

\section{Performance outcomes (grading)}

Although this aspect of using Twitter was only assessed in a few studies, most of them indicate that the platform supported students' performance with respect to grading. Those students that used more of Twitter in their classes ended up with much higher assignment scores and grade point averages than the rest of the students (Diug et al., 2016; Junco et al., 2013, 2011). Likewise, classes where Twitter was implemented as a supportive tool displayed higher learning as well as received higher grades than the counterparts (Clarke \& Nelson, 2012; Diug et al., 2016; Gonzalez \& Gadbury-Amyot, 2016). Due to limited research on the topic, a concrete decree cannot be established, hence this is one of the areas that merit further research.

\section{Retention}

A limited number of studies moreover focused on the retention rate once the use of Twitter was involved, but those that did found conflicting results. Some of these studies found that retention was significantly increased by the usage of Twitter in class, leading to an improved memory among students during testing (Blessing, Blessing, \& Fleck, 2012; Stephens \& Gunther, 2016). However, another study found no correlation between Twitter usage and increased retention in classes (Smith \& Tirumala, 2012). This particular aspect has little research and would be therefore an important area to explore further.

\section{Credibility}

A handful of research has been conducted to assess the credibility of instructors with relation to Twitter usage. For instance, DeGroot et al. (2015), found that students perceived those professors more credible whose Twitter profile featured posts about education, professional information and resources. Another study, further found that there was higher credibility among those professors that shared more personal information or had a socially active Twitter profile (Johnson, 2011). Due to limited research on this topic, this is another interesting research avenue that merits future research. 


\section{Future use intentions}

In general, respondents of various studies are quite positive about using the platform in the future. Most participants intended to continue using it for professional and teaching purposes, maintaining positive opinions about its usefulness (Carpenter et al., 2016; Carpenter \& Krutka, 2015; Hitchcock \& Young, 2016; Luo \& Franklin, 2015; Marín \& Tur, 2014). One of the key reason by students behind this is that they consider Twitter as a tool that encourages confidence and autonomous learning (Leis, 2014). Moreover, it encourages learning beyond the class content and many respondents desired to have more classes where Twitter is part of the curriculum (Menkhoff et al., 2015). Research also indicates that Twitter is also favored over other social media platforms by preservice teachers. For instance, a study by Mills (2014), point out that many pre-service teachers were aspired by Twitter as an auxiliary pedagogical tool and exhibited a strong desire and intention to introduce it in their future classes.

\section{Adverse perceptions and adoption obstacles}

Through our review, we also found several recurring negative aspects to Twitter usage within educational context. Distraction, information overload, privacy, and limited space for expression were some of the frequently reported issues. With the overwhelming amount of tweets, it was difficult for the users to keep up with the relevant content (Bull \& Adams, 2012; Cho \& Rangel, 2017; Davis, 2015; Fox \& Varadarajan, 2011; Gonzalez \& Gadbury-Amyot, 2016; Lin et al., 2013). This paired with another major concern that Twitter was too much of a distraction in the classroom when it came to taking notes and participating in class discussions (Fox \& Varadarajan, 2011; Mercier et al., 2015; Yakin \& Tinmaz, 2013). The same concern is also raised by respondents of another study by Wright et al. (2014), who found that Twitter distracted in-class face to face discussions and prevented them from taking important notes (Wright et al., 2014). Another related perception surfaced that Twitter was not conducive to course discussions or participation as many students were unable to participate in discussions on Twitter due to the presence of more knowledgeable and dominant experts of the field (Jacquemin et al., 2014; Lackovic et al., 2017). Due to this conception among learners, they preferred using other social media platforms that are not as professionaloriented as Twitter. For instance, the study by Mills (2014), reported that respondents favored using other social media tools (e.g. Facebook) to Twitter for learning purposes. Furthermore, study by Segado-Boj et al. (2015), regard Twitter as a platform for disseminating research but not for teaching purposes, as it serves more of a research showcase than a platform for collaboration. The same concern is also raised by Jacquemin et al. (2014), who reported that for the classroom setting, Twitter can be a suitable tool for information sharing purposes but not conducive to course discussions.

Many studies also reported logistical issues with usage and implementation of Twitter. Most of the first-time users did not foresee the benefits of using Twitter for educational purposes. This negative perception was mostly related to higher learning curve that required effort and time to gain command over various syntactical features and communication style native to Twitter (Bull \& Adams, 2012; Marr \& DeWaele, 2015; Stephens \& Gunther, 2016). Twitter was also seen as either too obtuse, or ineffective for formal discussion within the class, and unmanageable for larger classes (Jacquemin et al., 2014; Kassens, 2014). Due 
to learning curve, student resistance, and difficulty in judging the credibility of information, institutions find it challenging to expand the use and reach of Twitter (Kassens-Noor, 2012; Kimmons \& Veletsianos, 2016; Mysko \& Delgaty, 2015; Rinaldo et al., 2011).

In line with research on privacy aspects of social media (Malik et al. 2016), a number of studies also highlight students concerns over their right to privacy and how these concerns affected their Twitter use (DeGroot et al., 2015; Gonzalez \& Gadbury-Amyot, 2016; Rinaldo et al., 2011). With the growing use of the internet for professional purposes, concerns associated with online reputation were also flagged (Cho \& Rangel, 2017; Kinnison et al., 2017). There was also a concern for judgment and exposure within the class. Some students also displayed anxiety over grammatical correctness and the reactions from fellows and other users on the platforms (Kinnison et al., 2017). Similarly, another study also found that students used it infrequently and were unaware of the guidelines of using Twitter for educational purposes that led to anxiety towards its use and adoption (Gooding et al., 2016).

Moreover, the constricting nature of the 140 character limit (currently 280), was also considered challenging (Cohen \& Duchan, 2012; Luo \& Franklin, 2015). Due to restricted space to convey ideas through a tweet, the complexity and depth of students' thoughts got confined, and placed an unfair burden on them (Bledsoe et al., 2014; Carpenter, 2015). According to Bull and Adams (2012), this tended to force content in an unoriginal, baseless direction. Finally, another concern raised by Mysko and Delgaty (2015) in terms of instruction and learning through Twitter is that it is difficult to judge the credibility of information and sources particularly for students, which is highly critical in educational context.

\section{Implications for future research and practice}

When looking at the structure of the prior research, we have found that there is a lack of diversity within the studies conducted, as most of them are case studies and oriented towards few disciplines. This has left us with data that cannot be comfortably generalized. As it's not that long since Twitter got introduced in various educational settings, there has also been a severe lack of longitudinal studies. Similarly, there is a strong need as well as a desire within the academic community to further expand through exploiting digital trace data (netnography) and inferential data. With the greater amount of Twitter data and users currently accessible, both of these limitations can be addressed. With respect to studies carried out in various academic disciplines, there is a further need to conduct studies within arts and natural sciences as the research has so far concentrated on applied sciences and education domains.

We also observed some of the concerns with the tools that researchers have been using. While the use of Twitter for learning and engagement is important, we do not currently have a single holistic standard for learning as indicated by Carpenter et al., 2016. Similarly there is a lack of standard measurements of engagement indices and analysis of the usefulness of pedagogical analytics specifically focusing on the platform (Junco et al., 2011; Menkhoff et al., 2015). In addition, numerous studies use selfreporting as their main form of data collection. In order to have more representative data, comparing the reported findings to the actual usage (monitored data) of the respondents can also be fruitful for the domain (Hull \& Dodd, 2017). The overall push 
needs to use a more rigorous experimental design by collecting more quantitative data to support the current qualitative findings.

Next, the current understanding of Twitter in educational context has been confined that needs to further expanded. For instance, how Twitter can be more supportive for various learning contexts. Likewise, how Twitter can be promoted within these settings so that different entities are encouraged to adopt it for learning. There is also a strong need to further address the collaboration and connections formed on Twitter and how effective and lasting bonds can be formed over time in and outside the classroom. With so much negative press around the use of social media and the decline of cooperation and collaboration between students, this research could provide insight into how the use of social media can bring people together as opposed to creating barriers.

Investigating the use of Twitter for other educational settings than for learning purposes further can also be another valuable research avenue. For instance, Twitter can be a useful tool when planning a conference, but there is not enough evidence on how it affects the participants to have the extra influence (Jalali et al., 2015). In addition, there needs to be a further exploration of using Twitter as a backchannel and how this affects the participation and academic identity of individuals at conferences. The current research has another major limitation as the focus is usually towards a specific domain as the test subjects (for instance pre-service nurses and teachers) that limits the nuances of the platform used in other disciplines.

There is also a focus on comparing Twitter to the plethora of other teaching formats. The most basic of which is using Twitter versus not using it at all, or using the traditional method of teaching (Blessing et al., 2012; Luo, 2016; Veletsianos \& Kimmons, 2016; Visser et al., 2014). A detailed understanding towards the reasons why some instructors choose to use it while others do not will be highly supportive. Subsequently, there is also the issue of Twitter versus other forms of social media. Within this comes the question of whether or not learning benefits by the use of social media in general. However, if it is assumed that it does then the studies must turn to explore two options, the benefits of using Twitter over other types of social media, or the combination of Twitter and social media (Carpenter, 2014; West et al., 2015).

While there can be drawbacks to using Twitter, preliminary data has found that it has the potential to support professional development for both students and teachers (Carpenter, 2014; Carpenter \& Krutka, 2014, 2015). This is another area that requires additional research in order to gain more reliable data, as most of the research has been self-reported. However, if we were able to confidently state that Twitter had a positive impact on professional development, the platform could be used in innovative ways such as supporting teachers in developing countries and improving their training in more cost-effective ways (Carpenter, 2015). With such benefits to the use of Twitter in education, the most important direction in which future research should traverse is to understand the barriers associated with Twitter use. For instance investigating the perceptions of non-users, or why some teachers (as well as learners) who see the educational benefit of using Twitter avoid using the tool. Once we better understand these barriers, we can prioritize preferred social media for educational purposes with sound reasoning. Based on this understanding, strategies can be developed to circumvent barriers to enable more productive implementation of technology in the classroom. Finally, most of the analyzed studies span North America and Europe, yet there is a strong 
need to conduct more studies around the topic in other parts of the globe, particularly within Asian and African countries where the adoption rate of social media is phenomenal.

\section{Conclusions}

We analyzed 103 studies related to the use of Twitter in education. We found clear positive impact of integrating Twitter within classrooms for teaching and learning purposes. In non-classroom learning and other scholarly contexts (e.g. institutional use and conferences), Twitter strongly supports professional following and networking that ultimately resulted in improved teaching, learning, and collaboration. In both contexts, Twitter provides affordances for strongly connecting and bonding with others and forming a community. The platform also supports communication among the participants due to its real-time format and novel features. Furthermore, it provides them a channel for professional development and networking with peers, professionals, and authorities in their respective fields, with whom they can connect, communicate, share relevant resources, and follow prominent figures. Finally, many studies also point out that integrating Twitter within coursework motivated learners to participate actively, as most of them perceived it to be a highly effective non-traditional learning tool.

\section{Acknowledgements}

Not applicable.

Authors' contributions

AM planned and lead all the phases of the manuscript. CH supported in data analysis, and contributed in writing the manuscript. All authors read and approved the final manuscript.

Authors' information

Not applicable.

\section{Funding}

The work presented here is supported in part by U.S. National Science Foundation Award\#: 1424444, 1707837, 1712129, and 1741754. Dr. Malik partly contributed to this work as a postdoctoral scholar at GMU and Cassie's contribution was supported by a NSF REU. Any opinions, findings, and conclusions or recommendations expressed in this material are those of the authors and do not necessarily reflect the views of the funding agencies.

Availability of data and materials

The datasets used and/or analyzed during the current study are available from the corresponding author on reasonable request.

Competing interests

The authors declare that they have no competing interests.

Author details

${ }^{1}$ Department of Computer Science, Aalto University, Espoo 02150, Finland. ${ }^{2}$ Department of Information Sciences \& Technology, George Mason University, Fairfax, VA 22030, USA. ${ }^{3}$ William \& Mary, Williamsburg, VA 23187-8795, USA.

Received: 26 March 2019 Accepted: 1 August 2019

Published online: 25 September 2019

\section{References}

Al Harbi, M. (2016). Effects of twitter-assisted learning on developing literacy skills and motivation for learning in EFL settings. Arab Journal for the Humanities, 34(135), 268-292.

Alhabash, S., \& Ma, M. (2017). A tale of four platforms: Motivations and uses of facebook, twitter, instagram, and snapchat among college students. Social Media+ Society, 3(1) https://doi.org/10.1177/2056305117691544.

Andrade, A., Castro, C., \& Ferreira, S. A. (2012). Cognitive communication 2.0 in higher education: To tweet or not to tweet? Electronic Journal of E-Learning, 10(3), 293-305.

Anthony, B., \& Jewell, J. R. (2017). Students' perceptions of using twitter for learning in social work courses. Journal of Technology in Human Services, 35(1), 38-48.

Becker, R., \& Bishop, P. (2016). "Think bigger about science": Using twitter for learning in the middle grades. Middle School Journal, 47(3), 4-16.

Bista, K. (2015). Is twitter a pedagogical tool in higher education? Perspectives of education graduate students. Journal of the Scholarship of Teaching and Learning, 15(2), 83. 
Bledsoe, T. S., Harmeyer, D., \& Wu, S. F. (2014). Utilizing twitter and \#hashtags toward enhancing student learning in an online course environment. International Journal of Distance Education Technologies, 12(3), 75-83.

Blessing, S. B., Blessing, J. S., \& Fleck, B. K. B. (2012). Using twitter to reinforce classroom concepts. Teaching of Psychology, 39(4), 268-271. https://doi.org/10.1177/0098628312461484

Booth, R. G. (2015). Happiness, stress, a bit of vulgarity, and lots of discursive conversation: A pilot study examining nursing students' tweets about nursing education posted to twitter. Nurse Education Today, 35(2), 322-327. https://doi.org/ 10.1016/j.nedt.2014.10.012.

Bull, P. H., \& Adams, S. (2012). Learning technologies: Tweeting in a high school social studies class. I-Manager's Journal of Educational Technology, 8(4), 26.

Buzzelli, A., Bissell, J., \& Holdan, G. (2015). Analyzing Twitter's impact on student engagement in college instruction. International Journal of Information and Communication Technology Education, 12(2), 3-14.

Camiel, L. D., Goldman-Levine, J. D., Kostka-Rokosz, M. D., \& McCloskey, W. W. (2014). Twitter as a medium for pharmacy students' personal learning network development. Currents in Pharmacy Teaching and Learning, 6(4), 463-470.

Carpenter, J. (2014). Twitter's capacity to support collaborative learning. International Journal of Social Media and Interactive Learning Environments, 2(2), 103-118.

Carpenter, J. (2015). Preservice teachers' microblogging: Professional development via twitter. Contemporary Issues in Technology and Teacher Education, 15(2), 209-234.

Carpenter, J., \& Krutka, D. G. (2014). How and why educators use twitter: A survey of the field. Journal of Research on Technology in Education, 46(4), 414-434. https://doi.org/10.1080/15391523.2014.925701.

Carpenter, J., \& Krutka, D. G. (2015). Engagement through microblogging: Educator professional development via twitter. Professional Development in Education, 41(4), 707-728. https://doi.org/10.1080/19415257.2014.939294.

Carpenter, J., Tur, G., \& Marín, V. I. (2016). What do U.S. and Spanish pre-service teachers think about educational and professional use of twitter? A comparative study. Teaching and Teacher Education, 60, 131-143. https://doi.org/10.1016/j.tate.2016.08.011.

Cho, V., \& Rangel, V. S. (2017). The dynamic roots of school leaders' twitter use. JSLVol 26-N5, 26, 837.

Clarke, T. B., \& Nelson, C. L. (2012). Classroom community, pedagogical effectiveness, and learning outcomes associated with twitter use in undergraduate marketing courses. Journal for Advancement of Marketing Education, 20(2), 29-38.

Cohen, A., \& Duchan, G. (2012). The usage characteristics of twitter in the learning process. Interdisciplinary Journal of E-Learning and Learning Objects, 8(1), 149-163.

Davis, K. (2015). Teachers' perceptions of twitter for professional development. Disability and Rehabilitation, 37(17), 1551-1558.

DeGroot, J. M., Young, V. J., \& VanSlette, S. H. (2015). Twitter use and its effects on student perception of instructor credibility. Communication Education, 64(4), 419-437. https://doi.org/10.1080/03634523.2015.1014386.

Desselle, S. P. (2017). The use of twitter to facilitate engagement and reflection in a constructionist learning environment. Currents in Pharmacy Teaching and Learning, 9(2), 185-194. https://doi.org/10.1016/j.cptl.2016.11.016.

Diug, B., Kendal, E., llic, D., et al. (2016). Evaluating the use of twitter as a tool to increase engagement in medical education. Education for Health, 29(3), 223.

Dolan, R., Conduit, J., Fahy, J., \& Goodman, S. (2016). Social media engagement behaviour: A uses and gratifications perspective. Journal of Strategic Marketing, 24(3-4), 261-277.

Domizi, D. P. (2013). Microblogging to foster connections and community in a weekly graduate seminar course. TechTrends, 57(1), 43

Draper, J., Buzzelli, A. A., \& Holdan, E. G. (2016). Patterns of twitter usage in one cohort-based doctoral program. International Journal of Doctoral Studies, 11, 163-183

Elavsky, C. M., Mislan, C., \& Elavsky, S. (2011). When talking less is more: Exploring outcomes of Twitter usage in the large-lecture hall. Learning, Media and Technology, 36(3), 215-233. https://doi.org/10.1080/17439884.2010.549828.

Evans, C. (2014). Twitter for teaching: Can social media be used to enhance the process of learning?: Twitter for teaching. British Journal of Educational Technology, 45(5), 902-915. https://doi.org/10.1111/bjet.12099.

Feliz, T., Ricoy, C., \& Feliz, S. (2013). Analysis of the use of twitter as a learning strategy in master's studies. Open Learning: The Journal of Open, Distance and e-Learning, 28(3), 201-215. https://doi.org/10.1080/02680513.2013.870029.

Fewell, N. (2014). Social networking and language learning with twitter. Research Papers in Language Teaching and Learning, 5(1), 223.

Fox, B. I., \& Varadarajan, R. (2011). Use of twitter to encourage interaction in a multi-campus pharmacy management course. American Journal of Pharmaceutical Education, 75(5), 88

Gibbs, C., O'Reilly, N., \& Brunette, M. (2014). Professional team sport and twitter: Gratifications sought and obtained by followers. International Journal of Sport Communication, 7(2), 188-213. https://doi.org/10.1123/IJSC.2014-0005.

Goff, D. A., Jones, C., Toney, B., Nwomeh, B. C., Bauer, K., \& Ellison, E. C. (2016). Use of twitter to educate and engage surgeons in infectious diseases and antimicrobial stewardship. Infectious Diseases in Clinical Practice, 24(6), 324-327.

Gonzalez, S. M., \& Gadbury-Amyot, C. C. (2016). Using twitter for teaching and learning in an oral and maxillofacial radiology course. Journal of Dental Education, 80(2), 149-155.

Gooding, L. F., Yinger, O. S., \& Gregory, D. (2016). \#music students: College music students' twitter use and perceptions. Update: Applications of Research in Music Education, 34(2), 45-53.

Greenhalgh, S. P., Rosenberg, J. M., \& Wolf, L. G. (2016). For all intents and purposes: Twitter as a foundational technology for teachers. E-Learning and Digital Media, 13(1-2), 81-98. https://doi.org/10.1177/2042753016672131.

Greenwood, S., Perrin, A., \& Duggan, M. (2016). Social media update 2016 Retrieved August 14, 2017, from http://www. pewinternet.org/2016/11/11/social-media-update-2016/.

Halpin, P. A. (2016). Using twitter in a nonscience major science class increases students' use of reputable science sources in class discussions. Journal of College Science Teaching, 45(6), 71.

Haro-de-Rosario, A., Sáez-Martín, A., \& del Carmen Caba-Pérez, M. (2016). Using social media to enhance citizen engagement with local government: Twitter or Facebook? New Media \& Society. https://doi.org/10.1177/1461444816645652.

Helvie-Mason, L., \& Maben, S. (2017). Twitter-vism: Student narratives and perceptions of learning from an undergraduate research experience on twitter activism. Teaching Journalism \& Mass Communication, 7(1), 47.

Hennessy, C. M., Kirkpatrick, E., Smith, C. F., \& Border, S. (2016). Social media and anatomy education: Using twitter to enhance the student learning experience in anatomy: Use of twitter in anatomy education. Anatomical Sciences Education, 9(6), 505-515. https://doi.org/10.1002/ase.1610. 
Himelboim, I., \& Han, J. Y. (2014). Cancer talk on twitter: Community structure and information sources in breast and prostate cancer social networks. Journal of Health Communication, 19(2), 210-225. https://doi.org/10.1080/10810730.2013.811321.

Hitchcock, L. I., \& Young, J. A. (2016). Tweet, tweet!: Using live twitter chats in social work education. Social Work Education, 35(4), 457-468. https://doi.org/10.1080/02615479.2015.1136273.

Holmberg, K., \& Thelwall, M. (2014). Disciplinary differences in twitter scholarly communication. Scientometrics, 101(2), 10271042. https://doi.org/10.1007/s11192-014-1229-3.

Hsu, Y.-C., \& Ching, Y.-H. (2012). Mobile microblogging: Using twitter and mobile devices in an online course to promote learning in authentic contexts. The International Review of Research in Open and Distributed Learning, 13(4), 211-227.

Hull, K., \& Dodd, J. E. (2017). Faculty use of twitter in higher education teaching. Journal of Applied Research in Higher Education, 9(1), 91-104. https://doi.org/10.1108/JARHE-05-2015-0038.

Jacquemin, S. J., Smelser, L. K., \& Bernot, M. J. (2014). Twitter in the higher education classroom: A student and faculty assessment of use and perception. Journal of College Science Teaching, 43(6), 22-27.

Jalali, A., Sherbino, J., Frank, J., \& Sutherland, S. (2015). Social media and medical education: Exploring the potential of twitter as a learning tool. International Review of Psychiatry, 27(2), 140-146. https://doi.org/10.3109/09540261.2015.1015502

Johnson, K. A. (2011). The effect of Twitter posts on students' perceptions of instructor credibility. Learning, Media and Technology, 36(1), 21-38. https://doi.org/10.1080/17439884.2010.534798.

Johri, A., Karbasian, H., Malik, A., Handa, R., \& Purohit, H. (2018). How Diverse Users and Activities Trigger Connective Action via Social Media: Lessons from the Twitter Hashtag Campaign\# ILookLikeAnEngineer. In Proceedings of HICSS. Hawaii.

Jones, R., Kelsey, J., Nelmes, P., Chinn, N., Chinn, T., \& Proctor-Childs, T. (2016). Introducing twitter as an assessed component of the undergraduate nursing curriculum: Case study. Journal of Advanced Nursing, 72(7), 1638-1653. https://doi.org/ 10.1111/jan.12935.

Jordan, K. (2017). Examining the UK higher education sector through the network of institutional accounts on twitter. First Monday, 22(5). https://doi.org/10.5210/fm.v22i5.7133.

Juhary, J. (2016). Revision through twitter: Do tweets affect students' performance? International Journal of Emerging Technologies in Learning (IJET), 11(04), 4. https://doi.org/10.3991/ijet.v11i04.5124.

Junco, R., Elavsky, C., \& Heiberger, G. (2013). Putting twitter to the test: Assessing outcomes for student collaboration, engagement and success: Twitter collaboration \& engagement. British Journal of Educational Technology, 44(2), 273-287. https://doi.org/10.1111/j.1467-8535.2012.01284.x.

Junco, R., Heiberger, G., \& Loken, E. (2011). The effect of twitter on college student engagement and grades: Twitter and student engagement. Journal of Computer Assisted Learning, 27(2), 119-132. https://doi.org/10.1111/j.1365-2729.2010.00387.x.

Kassens, A. L. (2014). Tweeting your way to improved \#writing, \#reflection, and \#community. The Journal of Economic Education, 45(2), 101-109. https://doi.org/10.1080/00220485.2014.889937.

Kassens-Noor, E. (2012). Twitter as a teaching practice to enhance active and informal learning in higher education: The case of sustainable tweets. Active Learning in Higher Education, 13(1), 9-21.

Kim, E.-Y., Park, S.-M., \& Baek, S.-H. (2011). Twitter and implications for its use in EFL learning. Multimedia Assisted Language Learning, 14(2), 113-137.

Kimmons, R., \& Veletsianos, G. (2016). Education scholars' evolving uses of twitter as a conference backchannel and social commentary platform: Twitter backchannel use. British Journal of Educational Technology, 47(3), 445-464. https://doi.org/ 10.1111/bjet.12428.

Kimmons, R., Veletsianos, G., \& Woodward, S. (2017). Institutional uses of twitter in US higher education. Innovative Higher Education, 42(2), 97-111.

Kinnison, T., Whiting, M., Magnier, K., \& Mossop, L. (2017). Evaluating \#VetFinals: Can twitter help students prepare for final examinations? Medical Teacher, 39(4), 436-443. https://doi.org/10.1080/0142159X.2017.1296561.

Knight, C. G., \& Kaye, L. K. (2016). 'To tweet or not to tweet?' A comparison of academics' and students' usage of twitter in academic contexts. Innovations in Education and Teaching International, 53(2), 145-155. https://doi.org/10.1080/ 14703297.2014.928229.

Lackovic, N., Kerry, R., Lowe, R., \& Lowe, T. (2017). Being knowledge, power and profession subordinates: Students' perceptions of twitter for learning. The Internet and Higher Education, 33, 41-48. https://doi.org/10.1016/j.iheduc.2016.12.002.

Leis, A. (2014). Encouraging autonomy through the use of a social networking system. JALT CALL Journal, 10(1), 69-80.

$\mathrm{Li}$, J., \& Greenhow, C. (2015). Scholars and social media: Tweeting in the conference backchannel for professional learning. Educational Media International, 52(1), 1-14. https://doi.org/10.1080/09523987.2015.1005426.

Lin, M.-F. G., Hoffman, E. S., \& Borengasser, C. (2013). Is social media too social for class? A case study of twitter use. TechTrends, 57(2), 39

Liu, I., Cheung, C., \& Lee M. (2010). Understanding Twitter usage: What drive people continue to tweet. Proceedings of Pacific Asia Conference on Information Systems. Taipei, Taiwan.

Lomicka, L., \& Lord, G. (2012). A tale of tweets: Analyzing microblogging among language learners. System, 40(1), 48-63. https://doi.org/10.1016/j.system.2011.11.001.

Lowe, B., \& Laffey, D. (2011). Is twitter for the birds? Using twitter to enhance student learning in a marketing course. Journal of Marketing Education, 33(2), 183-192.

Luo, T. (2016). Enabling microblogging-based peer feedback in face-to-face classrooms. Innovations in Education and Teaching International, 53(2), 156-166. https://doi.org/10.1080/14703297.2014.995202.

Luo, T., \& Franklin, T. (2015). Tweeting and blogging: Moving towards education 2.0. International Journal on E-Learning, 14(2), 235-258.

Malik, A., Dhir, A., \& Nieminen, M. (2016). Uses and gratifications of digital photo sharing on Facebook. Telematics and Informatics, 33(1), 129-138.

Malik, A., Hiekkanen, K., \& Nieminen, M. (2016). Privacy and trust in Facebook photo sharing: age and gender differences. Program, 50(4):462-480.

Malik, A., Johri, A., Handa, R., Karbasian, H., \& Purohit, H. (2018). How social media supports hashtag activism through multivocality: A case study of\# ILookLikeanEngineer. First Monday, 23(11). https://doi.org/10.5210/fm.v23i11.9181.

Malik, A., Li, Y., Karbasian, H., Hamari, J., \& Johri, A. (2019). Live, love, Juul: User and content analysis of Twitter posts about Juul. American Journal of Health Behavior, 43(2), 326-336. 
Marín, V. I., \& Tur, G. (2014). Student teachers' attitude towards twitter for educational aims. Open Praxis, 6(3), 275-285.

Marr, J., \& DeWaele, C. S. (2015). Incorporating twitter within the sport management classroom: Rules and uses for effective practical application. Journal of Hospitality, Leisure, Sport \& Tourism Education, 17, 1-4. https://doi.org/10.1016/ j.jhlste.2015.05.001.

Menkhoff, T., Chay, Y. W., Bengtsson, M. L., Woodard, C. J., \& Gan, B. (2015). Incorporating microblogging ("tweeting") in higher education: Lessons learnt in a knowledge management course. Computers in Human Behavior, 51, 1295-1302. https://doi.org/10.1016/j.chb.2014.11.063.

Mercier, E., Rattray, J., \& Lavery, J. (2015). Twitter in the collaborative classroom: Micro-blogging for in-class collaborative discussions. International Journal of Social Media and Interactive Learning Environments, 3(2), 83-99.

Mills, M. (2014). Effect of faculty member's use of twitter as informal professional development during a preservice teacher internship. Education, 14(4), 451-467.

Moher, D., Liberati, A., Tetzlaff, J., Altman, D. G., Group, P, et al. (2009). Preferred reporting items for systematic reviews and meta-analyses: The PRISMA statement. PLoS Medicine, 6(7), e1000097.

Munoz, L. R., Pellegrini-Lafont, C., \& Cramer, E. (2014). Using social Media in Teacher Preparation Programs: Twitter as a means to create social presence. Penn GSE Perspectives on Urban Education, 11(2), 57-69.

Mysko, C., \& Delgaty, L. (2015). How and why are students using twitter for\# MEDED? Integrating twitter into undergraduate medical education to promote active learning. Annual Review of Education, Communication \& Language Sciences, 12, 24-52.

Nicholson, J., \& Galguera, T. (2013). Integrating new literacies in higher education: A self-study of the use of twitter in an education course. Teacher Education Quarterly, 40(3), 7-26.

Osatuyi, B., \& Passerini, K. (2016). Twittermania: Understanding how social media technologies impact engagement and academic performance of a new generation of learners. CAIS, 39, 23.

Osgerby, J., \& Rush, D. (2015). An exploratory case study examining undergraduate accounting students' perceptions of using twitter as a learning support tool. The International Journal of Management Education, 13(3), 337-348. https://doi.org/ 10.1016/j.jime.2015.10.002

Pollard, E. A. (2014). Tweeting on the backchannel of the jumbo-sized lecture hall: Maximizing collective learning in a world history survey. The History Teacher, 47(3), 329-354.

Prestridge, S. (2014). A focus on students' use of twitter-their interactions with each other, content and interface. Active Learning in Higher Education, 15(2), 101-115.

Quan-Haase, A., \& Young, A. L. (2010). Uses and gratifications of social media: A comparison of Facebook and instant messaging. Bulletin of Science, Technology \& Society, 30(5), 350-361.

Reames, B. N., Sheetz, K. H., Englesbe, M. J., \& Waits, S. A. (2016). Evaluating the use of twitter to enhance the educational experience of a medical school surgery clerkship. Journal of Surgical Education, 73(1), 73-78.

Rehm, M., \& Notten, A. (2016). Twitter as an informal learning space for teachers!? The role of social capital in twitter conversations among teachers. Teaching and Teacher Education, 60, 215-223. https://doi.org/10.1016/j.tate.2016.08.015.

Ricoy, M.-C., \& Feliz, T. (2016). Twitter as a learning community in higher education. Journal of Educational Technology \& Society, 19(1), 237

Rinaldo, S. B., Tapp, S., \& Laverie, D. A. (2011). Learning by tweeting: Using twitter as a pedagogical tool. Journal of Marketing Education, 33(2), 193-203. https://doi.org/10.1177/0273475311410852.

Rohr, L., \& Costello, J. (2015). Student perceptions of twitters' effectiveness for assessment in a large enrollment online course. Online Learning, 19(4), n4.

Ross, H. M., Banow, R., \& Yu, S. (2015). The use of twitter in large lecture courses: Do the students see a benefit? Contemporary Educational Technology, 6(2), 126-139.

Sauers, N. J., \& Richardson, J. W. (2015). Leading by following: An analysis of how K-12 school leaders use twitter. NASSP Bulletin, 99(2), 127-146.

Segado-Boj, F., Domínguez, M. Á. C., \& Rodríguez, C. C. (2015). Use of twitter among Spanish communication-area faculty: Research, teaching and visibility. First Monday, 20(6) https://doi.org/10.5210/fm.v20i6.5602.

Sinclair, W., McLoughlin, M., \& Warne, T. (2015). To twitter to woo: Harnessing the power of social media (SoMe) in nurse education to enhance the student's experience. Nurse Education in Practice, 15(6), 507-511. https://doi.org/10.1016/ j.nepr.2015.06.002.

Smith, J. E., \& Tirumala, L. N. (2012). Twitter's effects on student learning and social presence perceptions. Teaching Journalism \& Mass Communication, 2(1), 212.

Sotiriadis, M. D., \& van Zyl, C. (2013). Electronic word-of-mouth and online reviews in tourism services: The use of twitter by tourists. Electronic Commerce Research; New York, 13(1), 103-124. https://doi.org/10.1007/s10660-013-9108-1.

Steckenbiller, C. (2016). Am kürzeren Ende der Sonnenallee in 140 characters or less: Using twitter as a creative approach to literature in the intermediate German classroom. Die Unterrichtspraxis/Teaching German, 49(2), 147-160.

Stephens, T. M., \& Gunther, M. E. (2016). Twitter, millennials, and nursing education research. Nursing Education Perspectives, 37(1), 23-27.

Tess, P. A. (2013). The role of social media in higher education classes (real and virtual)-a literature review. Computers in Human Behavior, 29(5), A60-A68.

Tiernan, P. (2014). A study of the use of twitter by students for lecture engagement and discussion. Education and Information Technologies, 19(4), 673-690. https://doi.org/10.1007/s10639-012-9246-4.

Tur, G., \& Marín, V. I. (2015). Enhancing learning with the social media: Student teachers' perceptions on twitter in a debate activity. Journal of New Approaches in Educational Research, 4(1), 46.

Tur, G., Marín-Juarros, V., \& Carpenter, J. (2017). Using twitter in higher education in Spain and the USA. Comunicar, 25(51). https://doi.org/10.3916/C51-2017-02.

Twitter - Company. (2017). Retrieved August 14, 2017, from https://about.twitter.com/en_us.html.

Veletsianos, G. (2012). Higher education scholars' participation and practices on twitter: Scholars' participation and practices on twitter. Journal of Computer Assisted Learning, 28(4), 336-349. https://doi.org/10.1111/j.1365-2729.2011.00449.x.

Veletsianos, G., \& Kimmons, R. (2016). Scholars in an increasingly open and digital world: How do education professors and students use twitter? The Internet and Higher Education, 30, 1-10. https://doi.org/10.1016/j.iheduc.2016.02.002. 
Vergeer, M., \& Hermans, L. (2013). Campaigning on twitter: Microblogging and online social networking as campaign tools in the 2010 general elections in the Netherlands. Journal of Computer-Mediated Communication, 18(4), 399-419.

Visser, R. D., Evering, L. C., \& Barrett, D. E. (2014). \#TwitterforTeachers: The implications of twitter as a self-directed professional development tool for K-12 teachers. Journal of Research on Technology in Education, 46(4), 396-413. https://doi.org/ 10.1080/15391523.2014.925694

Waldrop, J., \& Wink, D. (2016). Twitter: An application to encourage information seeking among nursing students. Nurse Educator, 41(3), 160-163. https://doi.org/10.1097/NNE.0000000000000235.

Wang, Y. (2016). US state education agencies' use of twitter: Mission accomplished? SAGE Open, 6(1). https://doi.org/10.11 $77 / 2158244015626492$

Welch, B. K., \& Bonnan-White, J. (2012). Twittering to increase student engagement in the university classroom. Knowledge Management \& E-Learning: An International Journal (KM\&EL), 4(3), 325-345.

Wesely, P. M. (2013). Investigating the community of practice of world language educators on twitter. Journal of Teacher Education, 64(4), 305-318.

West, B., Moore, H., \& Barry, B. (2015). Beyond the tweet: Using twitter to enhance engagement, learning, and success among first-year students. Journal of Marketing Education, 37(3), 160-170.

Williams, D., \& Whiting, A. (2016). Exploring the relationship between student engagement, twitter, and a learning management system: A study of undergraduate marketing students. International Journal of Teaching and Learning in Higher Education, 28(3), 302-313.

Wright, N. (2010). Twittering in teacher education: Reflecting on practicum experiences. Open Learning: The Journal of Open and Distance Learning, 25(3), 259-265. https://doi.org/10.1080/02680513.2010.512102.

Wright, K. J., Frame, T. R., \& Hartzler, M. L. (2014). Student perceptions of a self-care course taught exclusively by team-based learning and utilizing twitter. Currents in Pharmacy Teaching and Learning, 6(6), 842-848. https://doi.org/10.1016/ j.cptl.2014.07.003

Yakin, I., \& Tinmaz, H. (2013). Using twitter as an instructional tool: A case study in higher education. TOJET: The Turkish Online Journal of Educational Technology, 12(4), 209-218.

\section{Publisher's Note}

Springer Nature remains neutral with regard to jurisdictional claims in published maps and institutional affiliations.

\section{Submit your manuscript to a SpringerOpen ${ }^{\circ}$ journal and benefit from:}

- Convenient online submission

- Rigorous peer review

- Open access: articles freely available online

High visibility within the field

- Retaining the copyright to your article

Submit your next manuscript at $\boldsymbol{\nabla}$ springeropen.com 